\title{
ENVIRONMENTAL NON-PERSISTENT ENDOCRINE-DISRUPTING CHEMICALS EXPOSURE AND REPRODUCTIVE HORMONES LEVELS IN ADULT MEN
}

\section{EMILA DZIEWIRSKA, WOJCIECH HANKE, and JOANNA JUREWICZ}

Nofer Institute of Occupational Medicine, Łódź, Poland

Department of Environmental Epidemiology

\begin{abstract}
Non-persistent endocrine-disrupting chemicals (EDCs) are exogenous, man-made substances present in the environment that may interfere with the natural human hormones and may exert adverse consequences on human organism. Endocrinedisrupting chemicals have been suspected to be associated with altered reproductive function in the case of males and females. Environmental endocrine-disrupting non-persistent chemicals like parabens, phthalates, bisphenol A (BPA), synthetic pyrethroids and organophosphate pesticides are found in various products such as metal food cans, plastic bottles, detergents, personal care products or chemicals used for fighting against insects. The widespread distribution of these chemicals causes that humans are permanently exposed through multiple sources. The aim of this review is to summarize data linking non-persistent endocrine-disrupting chemicals exposure, and human, male reproductive hormones levels. The included studies were selected by searched PubMed, Web of Science and MEDLINE, original papers published from 2006 to 2016 and referring to human data were included to the review. The results of reviewed studies were not consistent, however, majority of the studies indicated that non-persistent EDCs may affect male reproductive hormones levels. Most findings suggest that exposure to environmental EDCs is negatively related to the level of testosterone (except for exposure to BPA which is positively associated). In most of the studies negative association was found between exposure to examined EDCs and free androgen index, too. Considering the suggested health effect of exposure to EDCs, more epidemiological data is needed. Int J Occup Med Environ Health 2018;31(5):551-573
\end{abstract}

Key words:

Organophosphate pesticides, Bisphenol A, Parabens, Phthalates, Pyrethroids, Male reproductive health

\section{INTRODUCTION}

Infertility is defined clinically in the case of women and men who cannot achieve a clinical pregnancy after 1 or more of regular unprotected (at least 3 times in week) sexual intercourse [1]. A male factor is exclusively responsible in about $20 \%$ of infertile couples and contrib- utes to another $30-40 \%$ of couples [2]. There are many hypotheses in the increase of male infertility [3]. One of the hypothesis is the exposure to environmental factors especially substances with hormonal activity. The group of chemicals that could interfere with normal hormonal balance is named endocrine-disrupting chemi-

Funding: this study was supported by National Science Centre in Poland (grant No. UMO-2014/13/B/NZ7/02223 project entitled "The association between environmental exposure to widespread man made endocrine disrupting chemicals and level of hormones associated with the activity of hypothalamic pituitary testicular axis among young men," project manager: Wojciech Hanke, Ph.D.).

Received: January 31, 2017. Accepted: November 14, 2017.

Corresponding author: Emila Dziewirska, Nofer Institute of Occupational Medicine, Department of Environmental Epidemiology, św. Teresy 8, 91-348 Łódź, Poland (e-mail: emila.dziewirska@imp.lodz.pl). 
cals (EDCs) or endocrine disruptors (EDs). Endocrinedisrupting chemicals constitute a heterogeneous group of substances that interfere with endocrine function [4]. There is a number of official definitions of the EDCs. The most commonly used one is the following: "Endocrine-disrupting chemicals (EDCs) have been defined as exogenous agents that interfere with the production, release, transport, metabolism, binding, action, or elimination of the natural hormones in the body responsible for the maintenance of homeostasis and the regulation of developmental processes" by the United States Environmental Protection Agency (U.S. EPA) [5].

Toxicological and epidemiological studies on non-persistent environmental chemicals, such as: bisphenol A, phthalates, parabens, synthetic pyrethroids and organophosphate pesticides, which have relatively short half-lives in the human body and do not accumulate significantly, have also been reported to have endocrine-disrupting properties and are suspected to affect human reproduction and development [6]. The EDCs are observed in all places and countries where human biomonitoring studies have been performed. These substances are omnipresent in the environment and in mass-consumption products and food. Endocrine disruptors may be found in many products including plastic bottles, metal food cans, detergents, flame retardants, food, toys, cosmetics, and chemicals used for fighting against insects.

Human environmental exposure to EDCs takes place via ingestion of food, dust and water, via inhalation of gases and particles in the air, and through the skin [7]. Since such toxicants are omnipresent and it's hard to measure the amount of chemicals entering the body that is why there is disagreement about the degree of risk from exposure to EDCs [8]. Reproductive effect of EDCs exposure has been suspected for a long time, based on laboratory experiments and human epidemiological studies [9]. Due to temporal downward trends in semen quality and testosterone levels among adult men, researchers become increasingly concerned regarding potential risk of EDCs to men's reproductive health [10].

This review focuses on the human data regarding the relationship between environmental exposure to selected non-persistent EDCs (bisphenol A, phthalates, parabens, synthetic pyrethroids, organophosphate pesticides) in the case of adult men and male reproductive hormones levels, one of the predictor of male fertility.

\section{MATERIAL AND METHODS}

Epidemiological studies focused on the exposure to EDCs and male reproductive hormones levels were identified by means of searching databases. PubMeb, Web of Science and MEDLINE were systematically searched with detailed terms for: "bisphenol A," "phthalate," "parabens," "pyrethroids," "organophosphate pesticides" and "reproductive health," "reproductive hormones levels." Each of the first 5 keywords was combined with the 2 last keywords. The papers published from 2006 to 2016 were selected and only original articles were included. The period was chosen to reflect the finding over the past 10 years during which new techniques of measuring exposures and health effects in epidemiology studies have emerged. Articles focused on the animal and review or report papers were excluded. Studies regarding environmental exposure for adult men were included to the review. Papers concerning prenatal exposure to endocrine disruptors and male reproductive hormones levels were not taken into consideration. We included cohort, case-control cross-sectional, prospective and clinical studies that analyzed the impact of exposure to non-persistent EDCs on male reproductive hormones levels.

Data was independently extracted by 2 investigators who determined eligibility. Discrepancies were resolved by the third independent author. Finally 26 original studies concerning the association of non-persistent endocrinedisrupting chemicals and male reproductive hormones levels were classified to be reviewed. Contextual details of studies included in the systematic review are presented in 
the Table 1. The following data information was selected from the eligible papers: authors, the year published, the year studied, the design of study, the kind of endocrinedisrupting chemicals, exposure assessment, type of outcome, study population, the main conclusion, and the confounders or the potential risk factors. At last all the full-text articles were read in-depth to identify the aims of the studies, statistical methods and accurate results.

\section{RESULTS}

Details of the results are shown in the Table 2

\section{Bisphenol A and male reproductive hormones}

Bisphenol A (BPA) is used in the chemical industry as a monomer in the production of plastic. It is also an important ingredient in the production of epoxy resins [11]. This toxicant could be identified in toys, cans or baby bottles. Four papers concerning exposure to BPA and male reproductive hormones levels were identified and included in this review [12-15]. Two studies were conducted in the USA [12,13], one in Italy [14] and one in Denmark [15]. The most of the studies were cross-sectional, only Lassen et al. [15] performed an on-going prospective study among general population. In the 2 studies participants $[12,13]$ were recruited from medical centers. Galloway et al. (2010) [14] and Lassen et al. (2014) [15] recruited the participants from the general population. In all the reviewed studies total urinary concentrations of BPA (free + conjugated species) and serum reproductive hormones levels were measured.

Galloway et al. (2010) [14] noticed increasing levels of testosterone $(\mathrm{T})$ with increasing BPA concentration $(p=0.004)$. Similar findings were observed in Lassen et al. study (2014) [15] but additionally the authors observed increase in the levels of luteinizing hormone (LH) $(\mathrm{p}=0.005)$ and estradiol $\left(\mathrm{E}_{2}\right)(\mathrm{p}=0.006)$ in the highest quartile of BPA excretion (> $\left.6.44 \mathrm{ng} / \mathrm{ml}_{\text {osm }}\right)$. Meeker et al. (2010) [13] found a significant positive association between follicle-stimulating hormone $(\mathrm{FSH})(\mathrm{p}=0.0004)$ and BPA urinary concentration. An inverse association between inhibin B (INB) ( $p=0.003)$ and BPA was found, too. On the other hand Mendiola et al. (2010) [12] did not observe any association between exposure to BPA and FSH and INB concentration but noticed significant association with sex hormone binding globulin (SHBG) $(\beta=0.07$; 95\% CI: $0.007-0.13)$.

\section{Phthalate and male reproductive hormones}

Phthalates constitute a group of industrial chemicals with many commercial uses, including personal-care products, medical devices and plasticizers in the packing materials of food [16]. Several studies addressing links between urinary metabolites of phthalate and reproductive hormones levels in the case of men have been published for a few recent years [17-27]. In the review 12 papers were included. Most of these studies were cross-sectional. Four of the studies were conducted in China [22,26,27], two in the USA and Denmark [18,19], one in Poland [21], in India [23], in Sweden [25] - and Specht et al. (2014) [24] performed a multicenter study where subjects were recruited in Poland, Ukraine and Greenland. Most of these participants were enrolled during visits in medical centers [18,19,21,23,24,26,27]. Reproductive hormones levels were measured in serum in all the presented studies. In the case of exposure assessment the levels of phthalate metabolites were mostly measured in urine [18-22,25,26]. Whereas Pant et al. (2014) [23] and Wang et al. (2016) [27] assessed the seminal concentrations of phthalates and Specht et al. (2014) [24] as well as Janjua et al. (2007) [17] investigated levels of phthalate metabolites in serum. Mendiola et al. (2011) [19], Joensen et al. (2012) [20] and Pan et al. (2015) [26] found the negative association between phthalate and free androgen index, additionally Mendiola et al. (2011) [19] reported inverse association between some metabolites of phthalate (mono(2-ethylhexyl) phthalate (MEHP), mono(2-ethyl-5-hydroxyhexyl) 


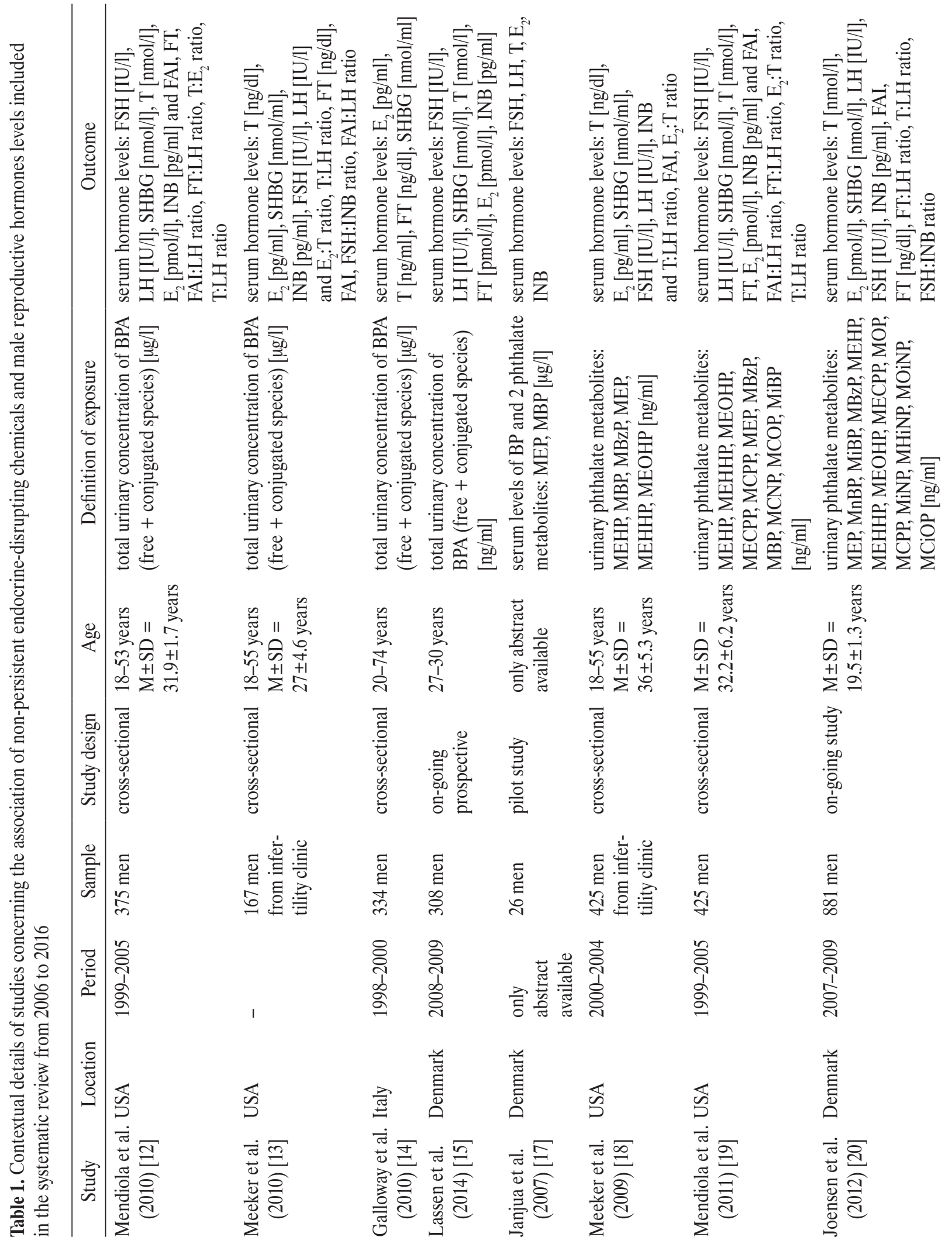




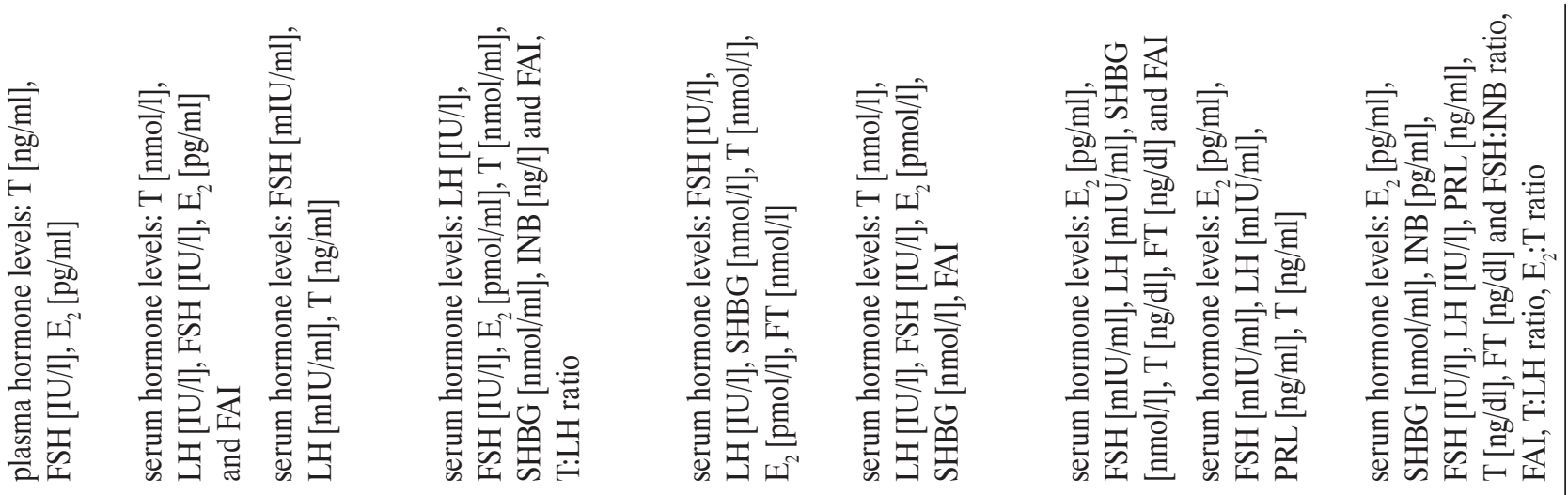

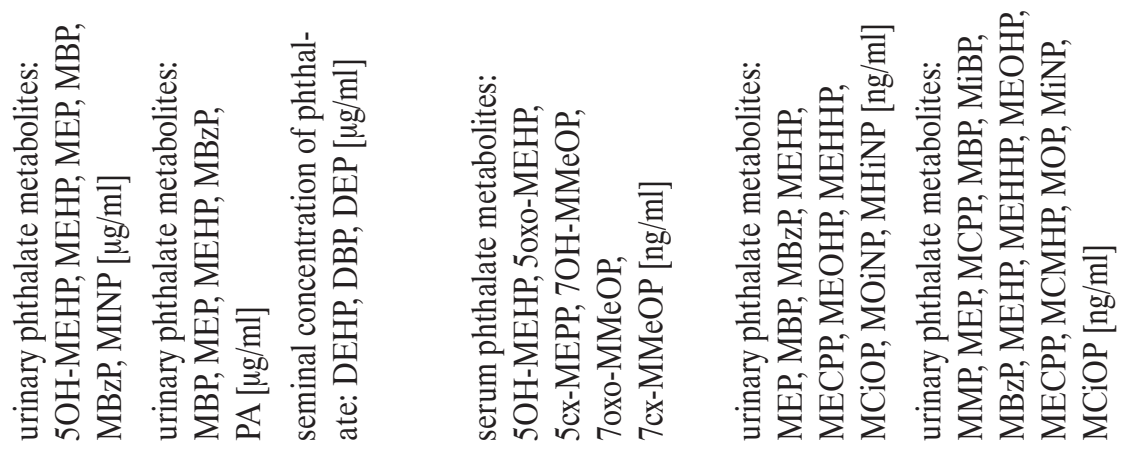
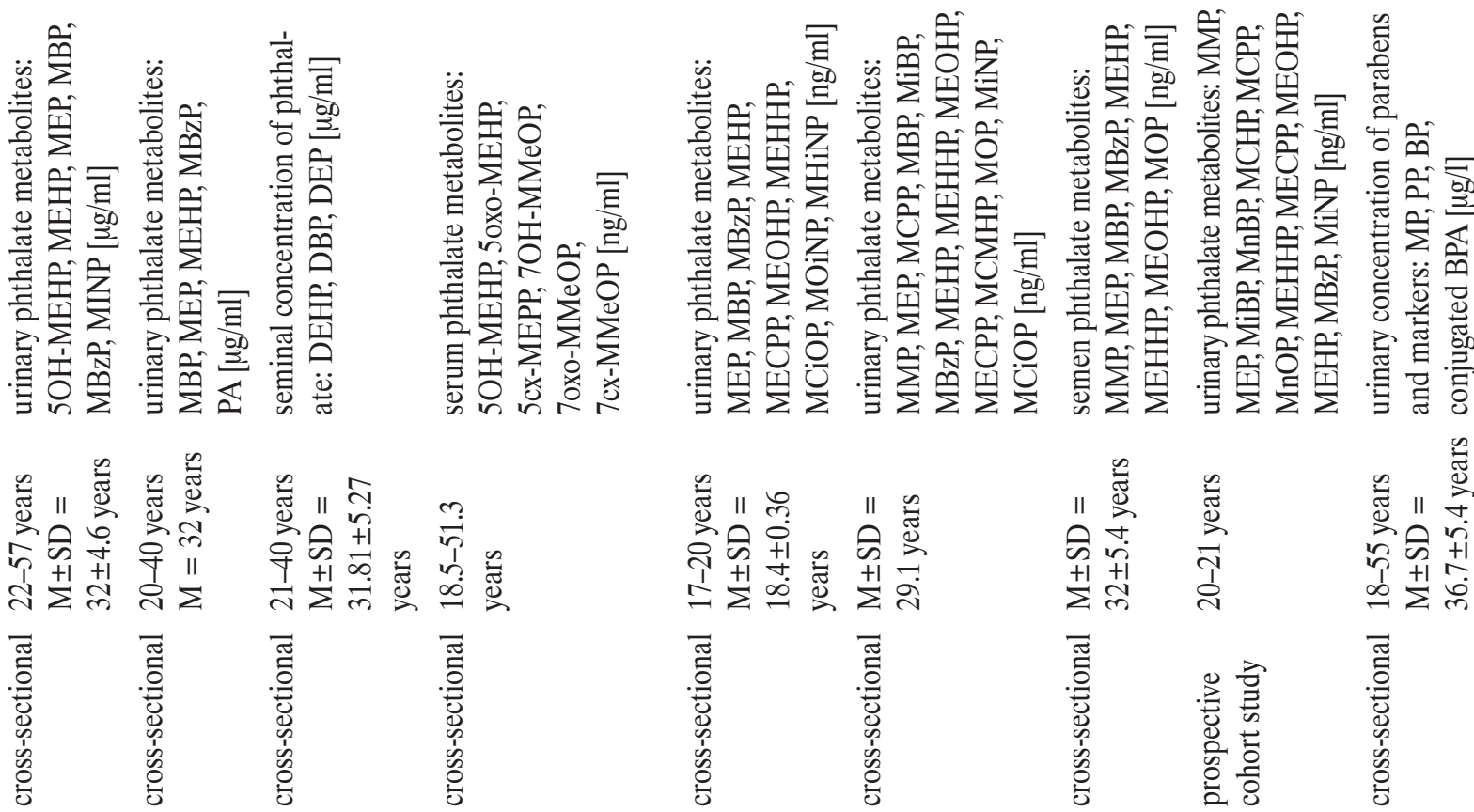

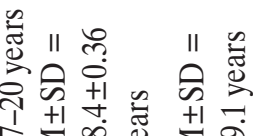

盖善

范

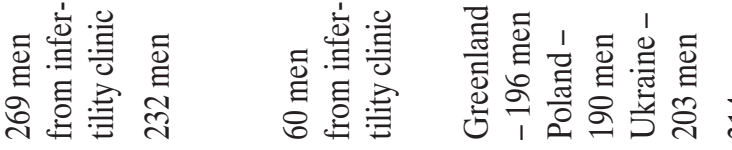

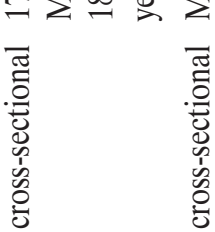

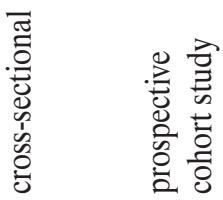

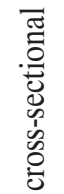

, ริ

흐ำ

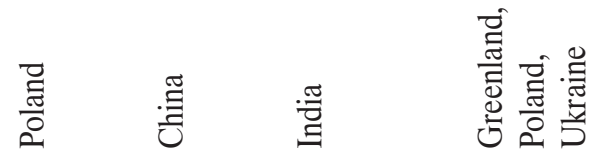

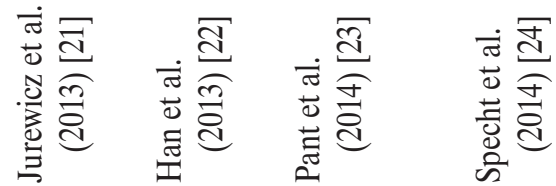

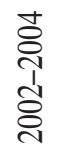

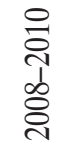

I

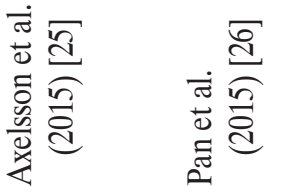

部音

ते
ते
ते
ते

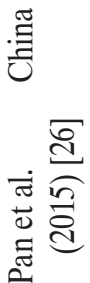

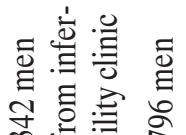

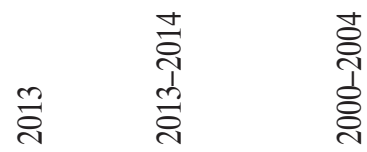

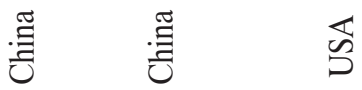

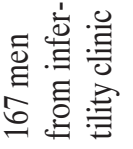

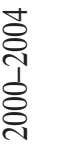

$\underset{b}{\square}$ 


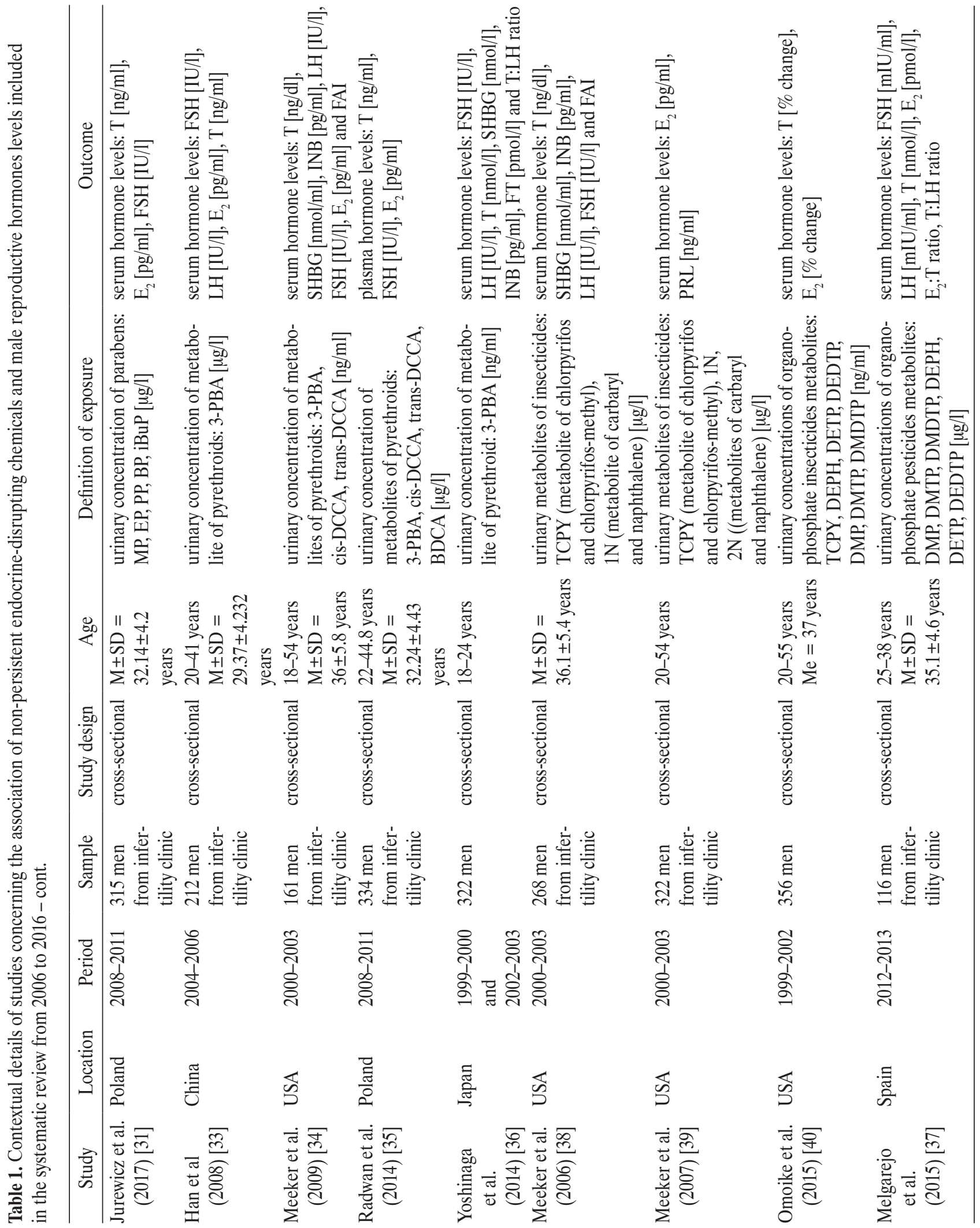




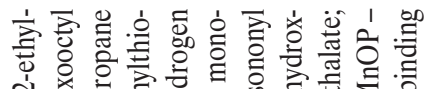

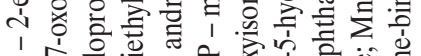

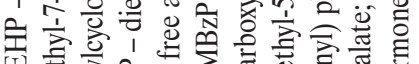

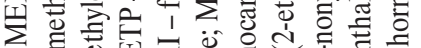

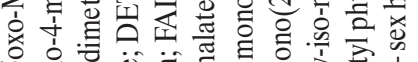

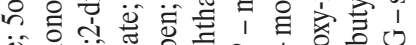

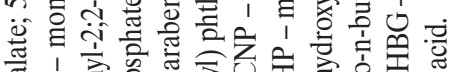

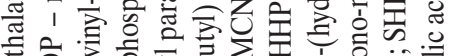

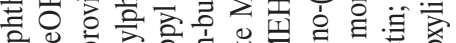

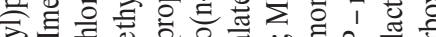

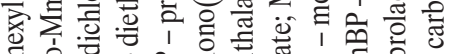

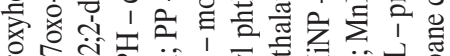

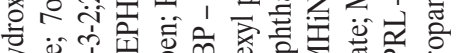

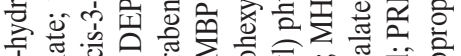
宊

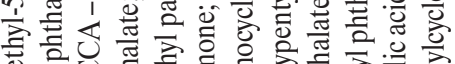

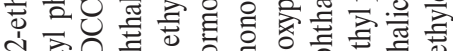

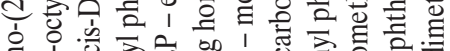

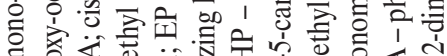

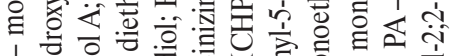

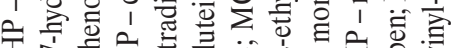

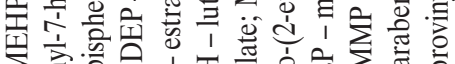
$\sum_{1}{ }_{1}^{2}$

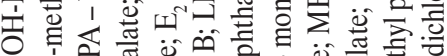

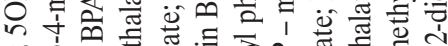
仓े

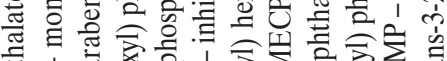

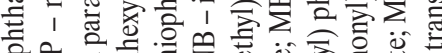

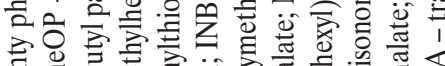

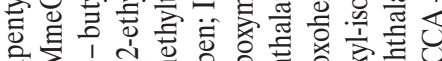

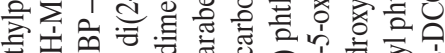

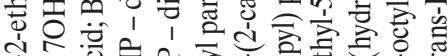

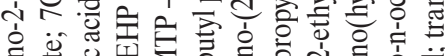

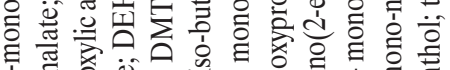

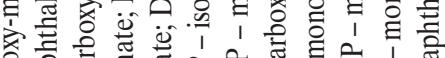

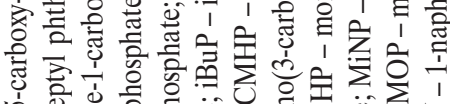

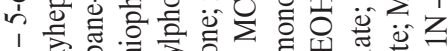

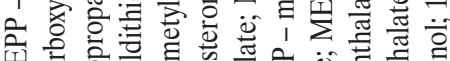

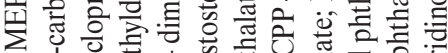

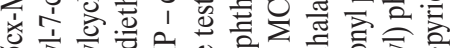

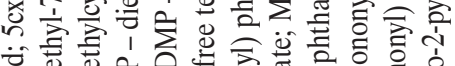

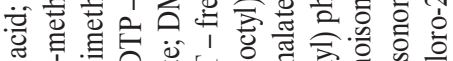

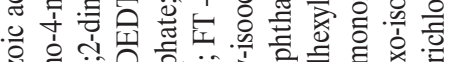

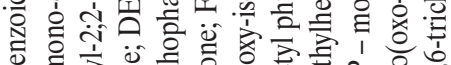

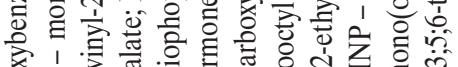

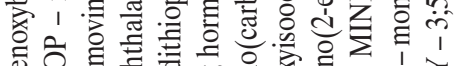

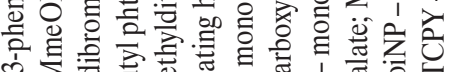

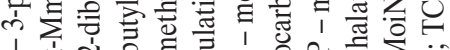

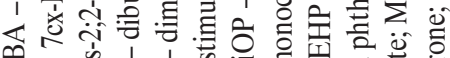

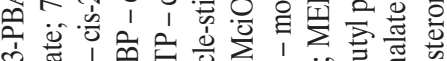
๙

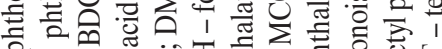

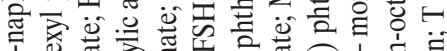

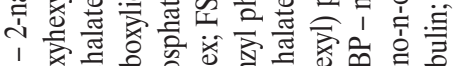

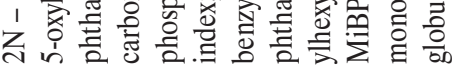

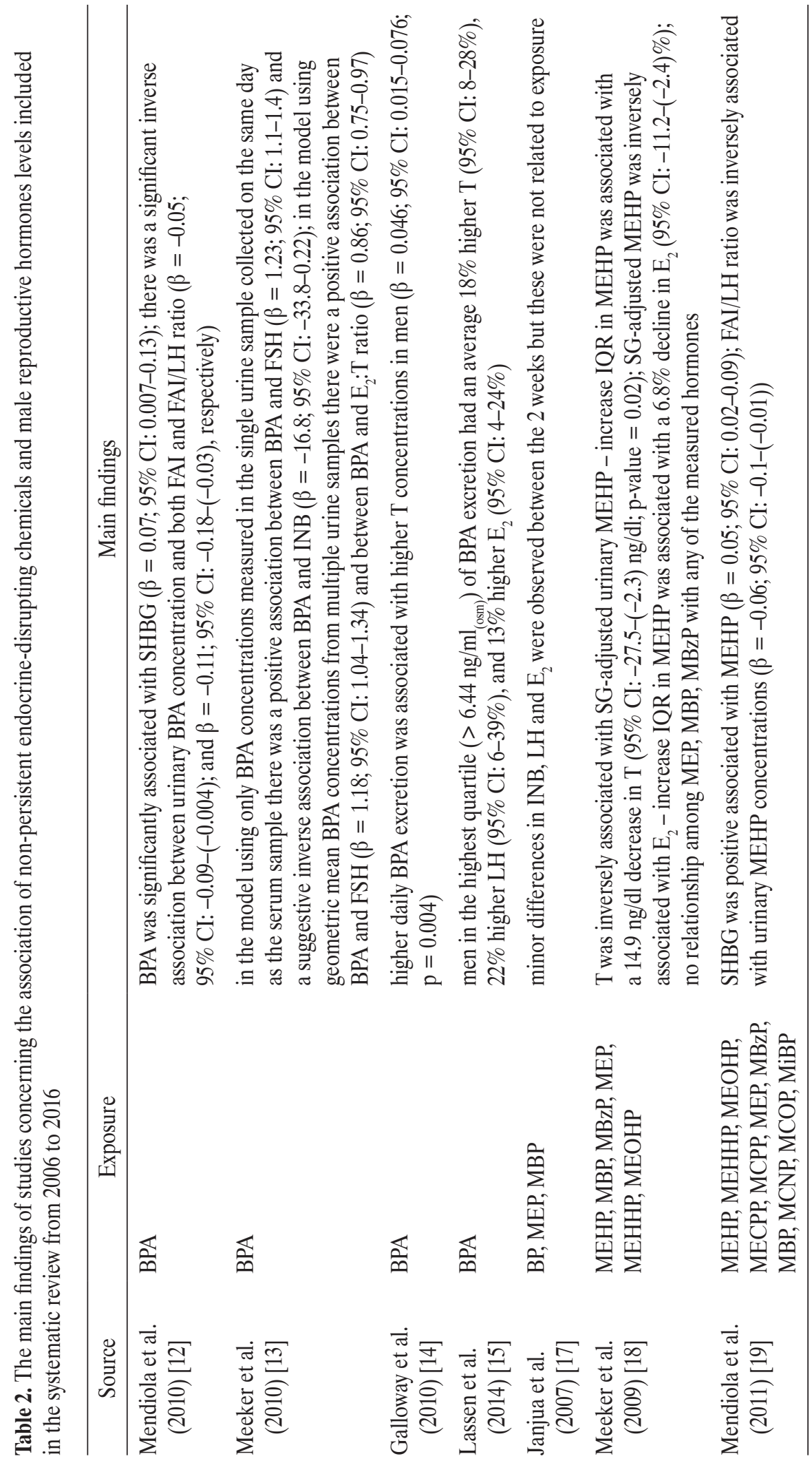




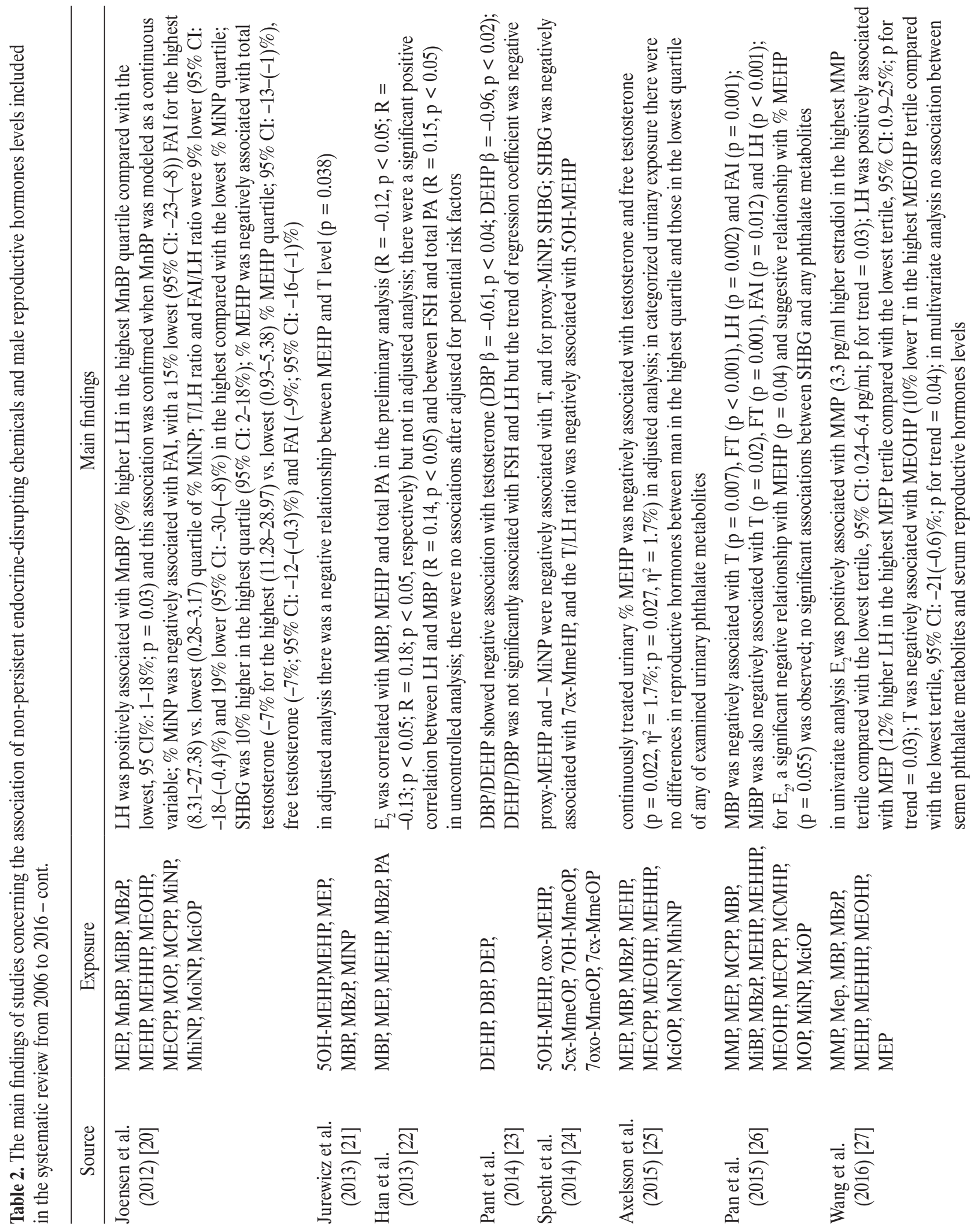



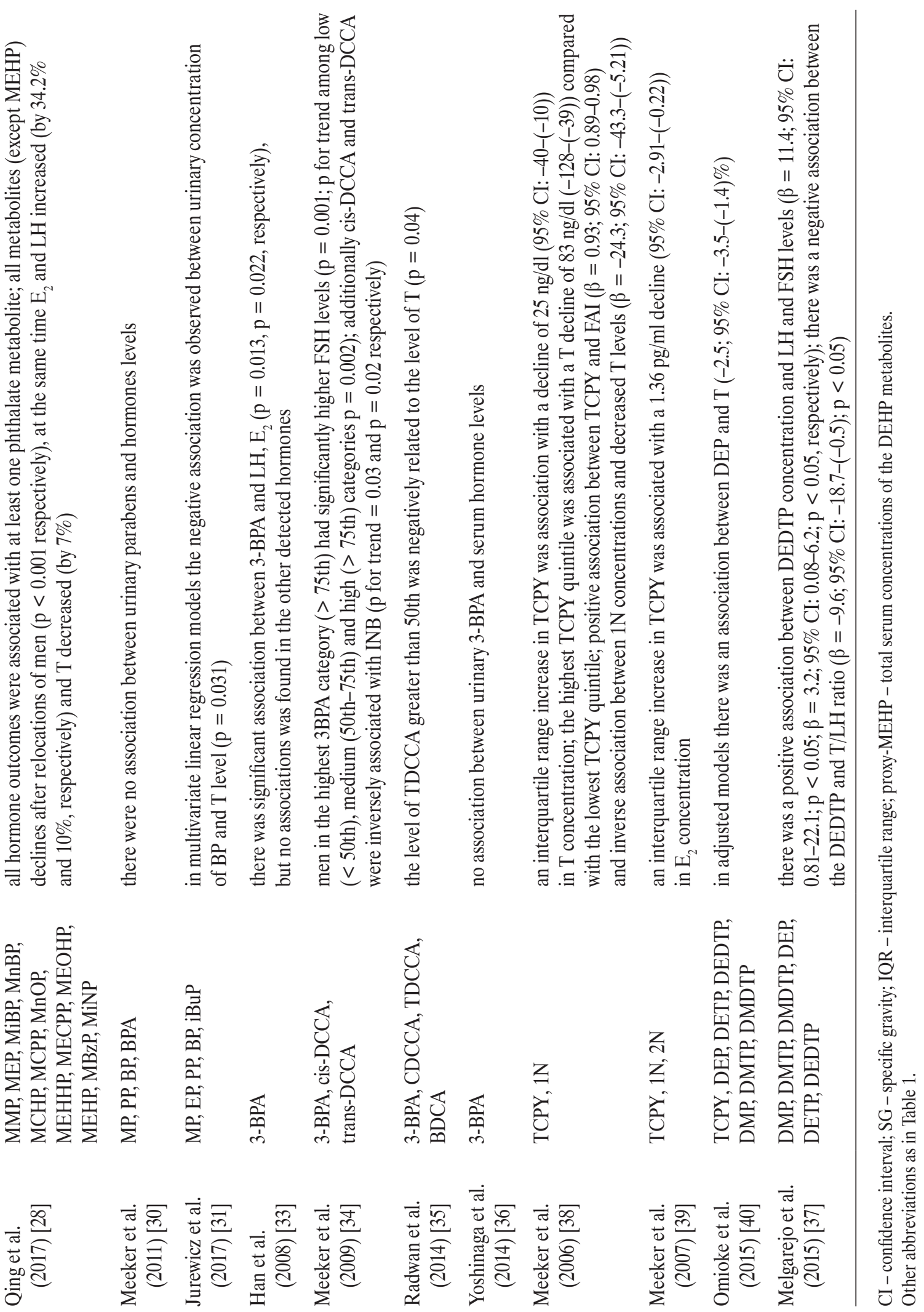
phthalate (MEHHP), mono(2-ethyl-5-oxohexyl) phthalate (MEOHP) and mono (2-ethyl-5-carboxypentyl) phthalate (MECPP) and free testosterone. The study conducted by Axelsson et al. (2015) [25] indicated that \% MEHP was negatively associated with testosterone $(\mathrm{T})(\mathrm{p}=0.022$, $\left.\eta^{2}=1.7 \%\right)$ and free testosterone (FT) $(p=0.027$, $\eta^{2}=1.7 \%$ ) in the adjusted model. In the prospective ongoing study conducted by Qing [28] all hormone outcomes were associated with at least one phthalate metabolite. A comparison of phthalate metabolites between baseline and the follow-up showed that all but MEHP substantially declined after the relocation ( $\mathrm{p}<0.001$ respectively). At the same time $\mathrm{E}_{2}$ and $\mathrm{LH}$ increased (by $34.2 \%, 10 \%$, respectively), and $\mathrm{T}$ decreased (by 7\%). In all the remaining studies exposure to phthalate was negatively associated with testosterone levels [18-21,23-26], too. Whereas Wang et al. (2016) [27] and Han et al. (2013) [22] didn't find any significant association between phthalate exposure and serum reproductive hormones levels. Janjua et al. [17] conducted the clinical study on 26 healthy young male volunteers which were assigned to daily whole body topical application of $2 \mathrm{mg} / \mathrm{cm}^{2}$ basic cream formulation each without and with the $2 \%$ compounds. Authors did not reveal any short-term influence on the reproductive hormones levels in the case of the examined men.

\section{Parabens and male reproductive hormones}

Parabens are extensively used as antimicrobial preservatives in food, cosmetics, toiletries and pharmaceuticals [29]. According to our knowledge only 3 studies examine the association between exposure to parabens and reproductive hormones in the case of men [17,30,31]. The studies were conducted in Poland, Denmark and USA. Jurewicz et al. (2017) [31] and Meeker et al. (2011) [30] assessed urinary concentrations of parabens whereas Janjua et al. (2007) [17] assessed serum level of butyl paraben (BP). In all the remaining studies reproductive hormones levels were measured in serum. Jurewicz et al. [31] showed that BP was negatively associated with the level of testosterone ( $\mathrm{p}=0.031)$. While Janjua et al. [17] and Meeker et al. [30] did not reveal any association between exposure to parabens and serum hormone levels. Further studies are necessary to clarify the association between environmental exposure to parabens and reproductive hormones levels in the case of adult men.

\section{Synthetic pyrethroids and male reproductive hormones}

Synthetic pyrethroids constitute the class of insecticides and are found in many formulations used in agriculture for controlling insect pests in crops, forestry and in gardens. They are also widely used as insecticides in household and public buildings [32]. Synthetic pyrethroids are most common insecticides used nowadays [32]. These chemicals possess hormonal activities and have also been classified as endocrine disruptors [33]. In the review 4 original papers concerning the relationship between synthetic pyrethroids and male reproductive hormones were included [33-36]. The studies were conducted in China [33], USA [34], Poland [35] and Japan [36]. All the participants were recruited from medical centers except for Yoshinaga et al. (2014) [36] where the participants were students from Kawasaki.

Exposure to synthetic pyrethroids was assessed by measuring pyrethroids metabolites in urine: 3-phenoxybenzoic acid (3-PBA) [33-36], cis-3-(2,2-dichlorovinyl)-2,2dimethylocyclopropane carboxylic acid (CDCCA), trans3-(2,2-dichlorovinyl)-2,2-dimethylocyclopropane carboxylic acid (TDCCA) [34,35] and cis-2,2-dibromovinyl-2,2dimethylcyclopropane-1-carboxylic acid (DBCA) [35]. Radwan et al. (2014) [35] showed that the level of TDCCA greater than 50th was negatively related to the level of $\mathrm{T}(\mathrm{p}=0.04)$ but there was no association between reproductive hormones and other pyrethroids metabolites (CDCCA, 3PBA, DBCA). In the study performed by Han et al. [33] significant association was found between 3-PBA and LH, $\mathrm{E}_{2}(\mathrm{p}=0.013, \mathrm{p}=0.022$, respec- 
tively). These results are similar to those of Meeker et al.'s study (2009b) [34], where suggestive positive association with LH was also found $(\mathrm{p}=0.054)$. Additionally, men in the highest 3 -PBA category ( $\geq 75$ th percentile) had significantly higher FSH levels $(\mathrm{p}=0.001)$ and had a suggestive decline in free androgen index (FAI) $(\mathrm{p}=0.08)$, too. Furthermore, cis-DCCA and trans-DCCA were negatively associated with inhibin $\mathrm{B}$ ( $\mathrm{p}$ for trend $=0.03$ and $\mathrm{p}$ for trend $=0.02$, respectively). On the other hand Yoshinaga et al. (2014) [36] revealed that there was no associations between urinary 3-BPA and reproductive hormones levels.

\section{Organophosphate pesticides and male reproductive hormones}

Organophosphate pesticides are used in agricultural and household for pest control [37]. These chemicals are widely used in agriculture and commerce [38]. Due to extensive use of such pesticides, a large proportion of the population is exposed to these chemicals or their environmental degradation products. Four original papers referring to exposure to organophosphate pesticides and levels of reproductive hormones were included in the review [37-40]. Three of the studies were conducted in the USA [38-40] and one in Spain [37]. All of the studies were cross-sectional. Participants were male partners in couples presenting to an infertility clinics, except for Omoike et al. (2015) [40] who derived data (subset of men $(\mathrm{N}=356)$ ) from the crosssectional US National Health and Nutrition Examination Survey (NHANES).

In all reviewed studies serum hormones levels and urinary concentrations of metabolites of pesticides were measured. Meeker et al. $(2006,2007)[38,39]$ assessed the metabolites of chlorpyrifos, carbaryl, naphthalene: 3,5,6-trichloro-2-pyridinol (TCPY), 1-naphthol (1N), 2-naphthol (2N) whereas Omoike et al. (2015) [40] and Melgarejo et al. (2015) [37] measured 6 non-specific urinary metabolites of chlorpyrifos and chlorpyrifos-methyl: diethylphosphate (DEPH), diethylthiophosphate (DETP), diethyldithiophosphate (DEDTP), dimethylphosphate (DMP), dimethylthiophosphate (DMTP), dimethyldithiophosphate (DMDTP). Both studies performed by Meeker et al. $(2006,2007)[38,39]$ indicated that there was an inverse association between urinary metabolites of non-persistent insecticides and reproductive hormones levels. Negative association between TCPY and testosterone concentration was found [38]. Interquartile range increase in TCPY was associated with a decline of $25 \mathrm{ng} / \mathrm{dl}$ (95\% CI: $-40-(-10))$ in testosterone level and the highest TCPY quintile was associated with a testosterone decline of $83 \mathrm{ng} / \mathrm{dl}$ (95\% CI: -128-(-39)) as compared with the lowest TCPY quintile [38]. The next study performed by Meeker et al. (2007) [39] revealed that an interquartile range increase in TCPY was associated with a $1.36 \mathrm{pg} / \mathrm{ml}$ decline (95\% CI: -2.91-(-0.22)) in $\mathrm{E}_{2}$ concentration. Whereas Omoike et al. (2015) [40] observed a statistically significant inverse association between DEPH and testosterone $(-2.5$; 95\% CI: $-3.5-(-1.4))$ when exposure was modeled as both a continuous or a categorical variable. The results are not consistent with Melgarejo et al. (2015) [37], where only DEDTP concentration was positively associated with serum LH and FSH concentrations levels ( $\beta=11.4$; 95\% CI: 0.81-22.1; $p<0.05$; $\beta=3.2 ; 95 \%$ CI: 0.08-6.2; $p<0.05$, respectively).

\section{DISCUSSION}

\section{Main findings}

The results of the reviewed original papers suggest that environmental exposure to non-persistent endocrine-disrupting chemicals may affect reproductive hormones levels. The summary of the results is presented in the Table 3 . The results of studies analyzing the association between exposure to bisphenol $\mathrm{A}$ and male reproductive hormones levels (T, LH, FSH, SHBG, $\mathrm{E}_{2}$, INB, prolactin (PRL)) are not consistent. When some results suggest that BPA was positively associated with some reproductive hormones levels, other studies didn't find such associations. Mendio- 


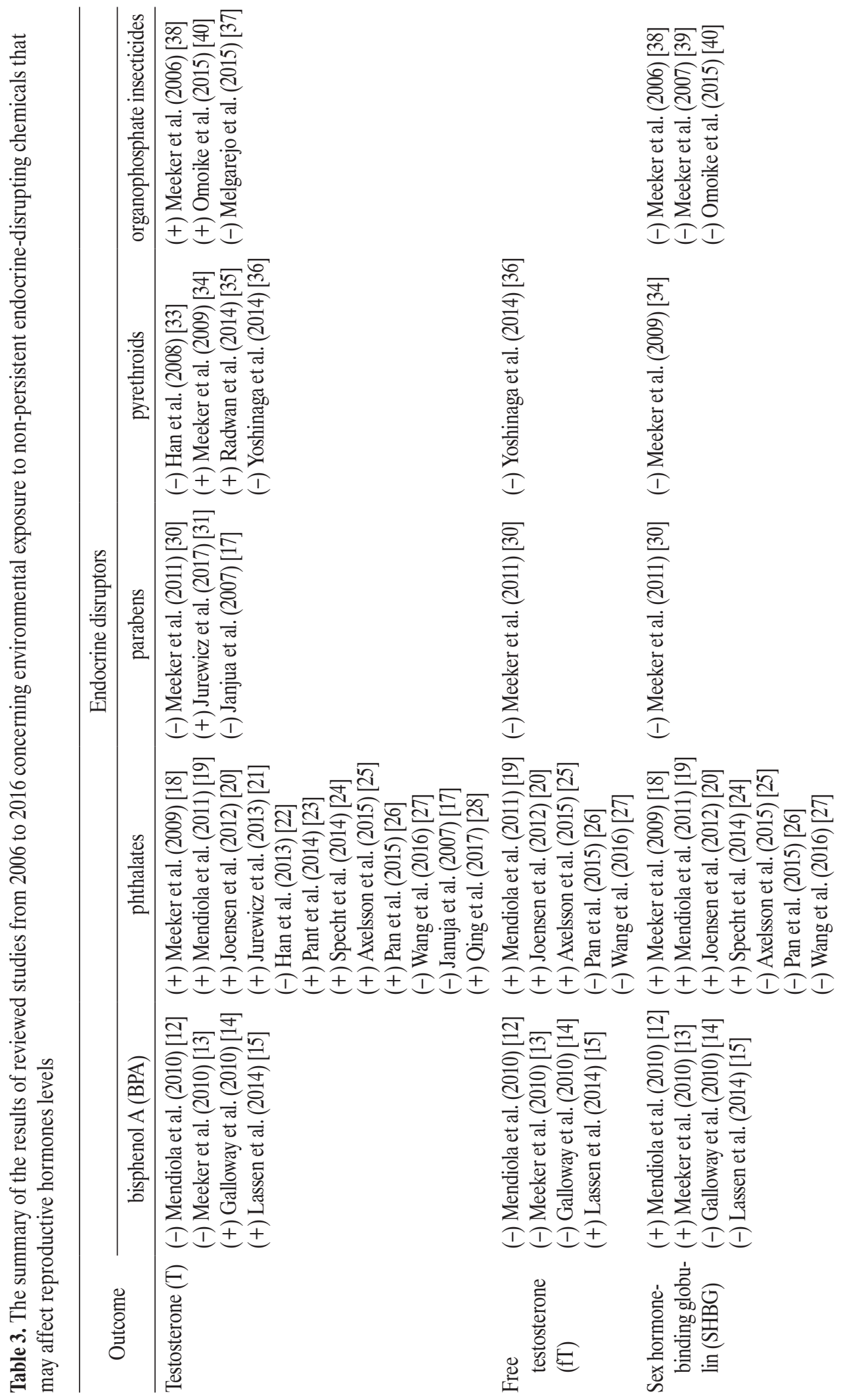




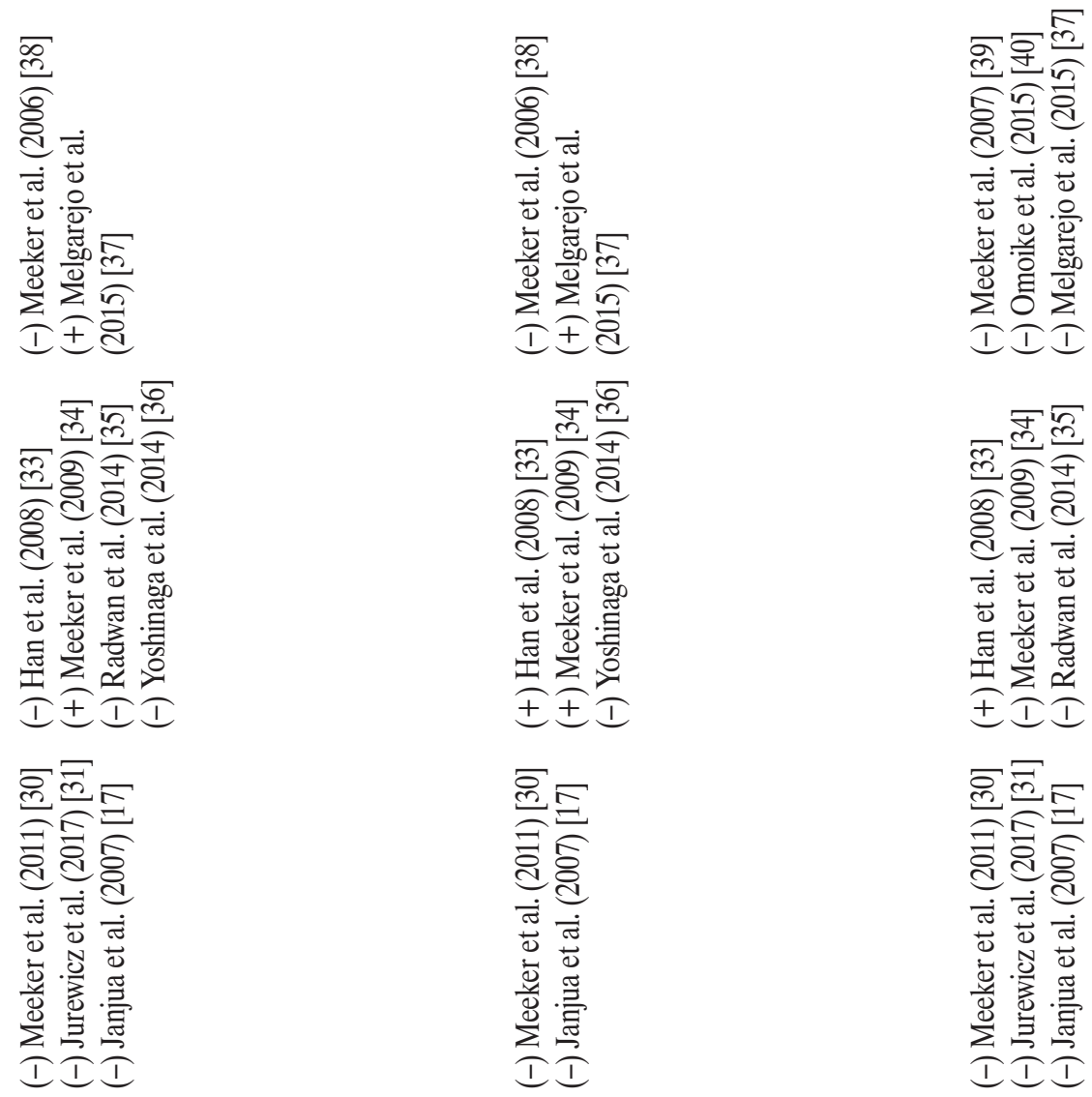

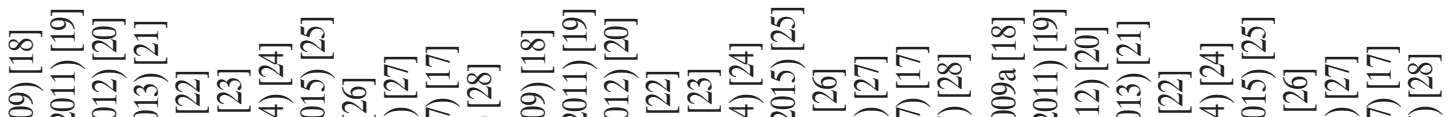

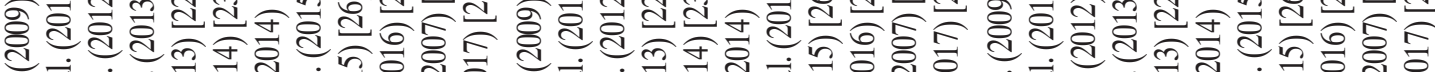
元

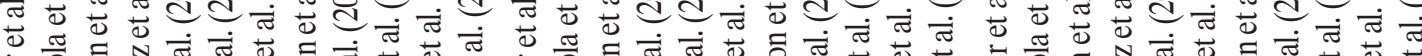

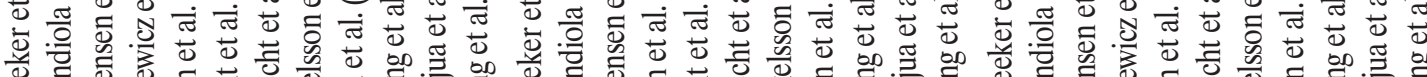

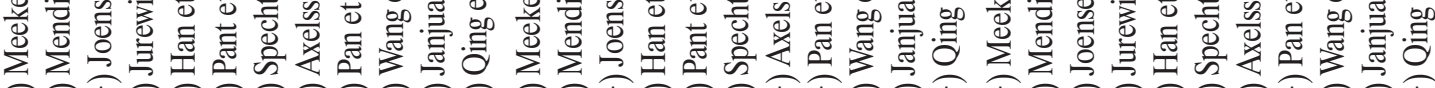
IIIIIIIIIIIII IIIIIIIIIIII

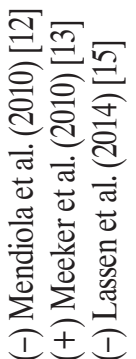

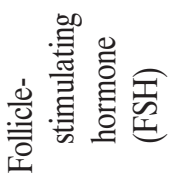
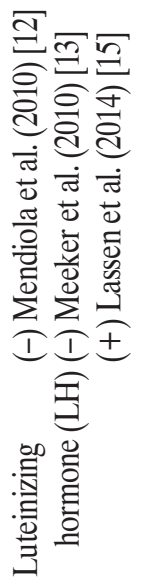

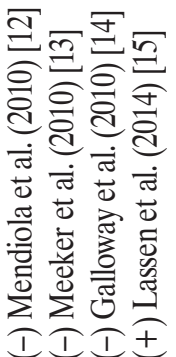

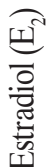




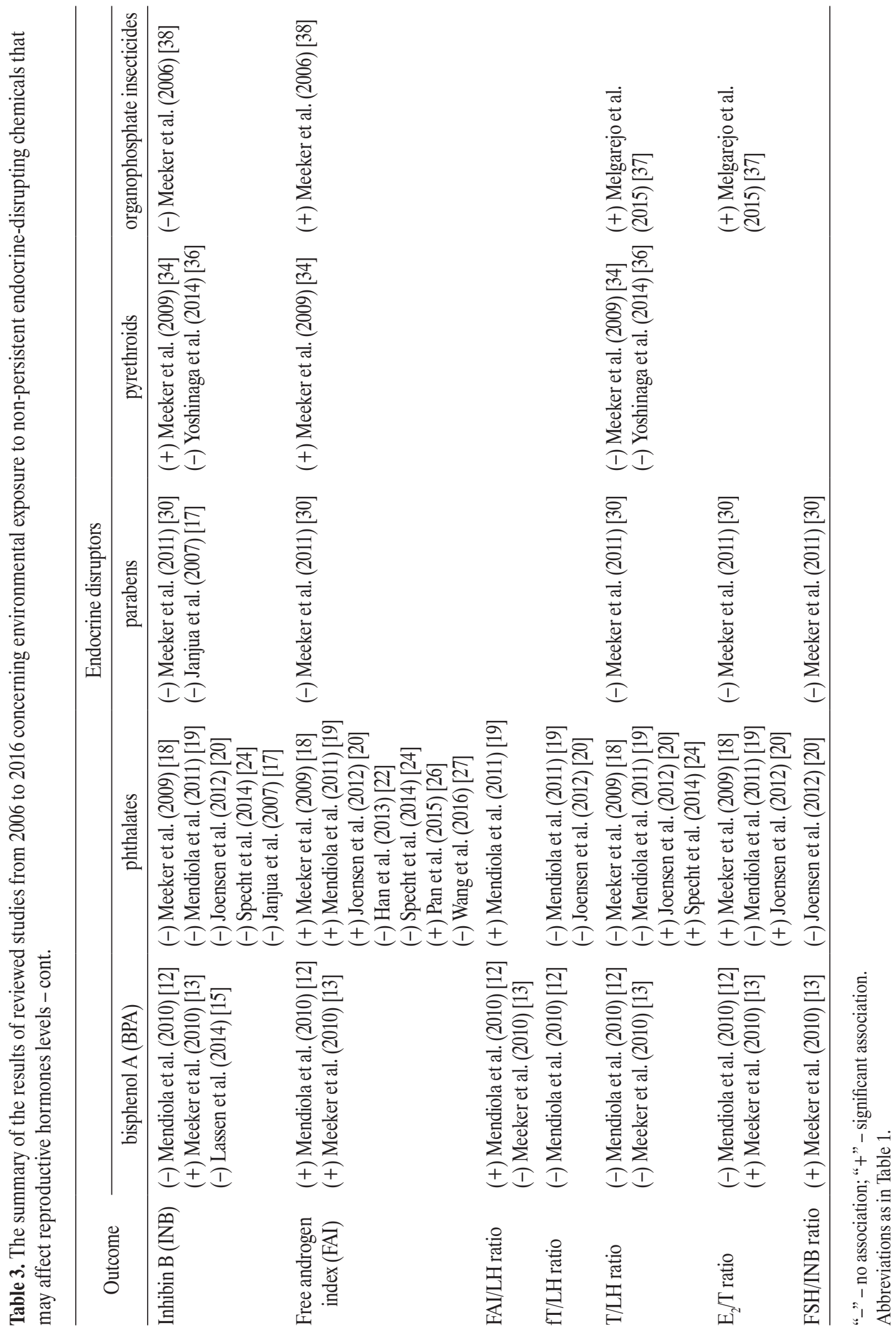


la et al. (2010) [12] and Meeker et al. (2010) [13] revealed that BPA was positively associated with SHBG but in Galloway et al.'s (2010) [14] and Lassen et al.'s (2014) [15] studies there were no similar associations. Likewise, the results of studies referring to phthalates and male reproductive hormones are not consistent. Three [27,22] of the 10 studies did not find any association between the exposure to phthalates and the level of reproductive hormones in the case of men in adjusted models. The rest of the studies [18-21,23-26] revealed that at least one of the phthalate metabolites was associated with decline in the level of testosterone. Some authors $[18,20,26]$ also revealed that exposure to phthalate was inversely associated with $\mathrm{E}_{2}$ and free androgen index. Three studies [17,30,31] assess the relationship between exposure to parabens and male reproductive hormones levels and only in the study performed by Jurewicz et al. [31] the level of urine BP was negatively associated with testosterone. Two of the studies $[17,30]$ found no evidence for this association. However, it is possible that intraindividual variability in exposure and small sample size could have limited ability to reveal subtle associations.

The results of studies analyzing the associations between exposure to synthetic pyrethroids and male reproductive hormones have some differences in results as well. While Yoshinaga et al. (2014) [36] revealed no evidence for those associations, other authors suggested that environmental pyrethroids exposure may have affected the level of reproductive hormones. Han et al. (2008) [33] and Meeker et al. (2009b) [34] noticed positive associations between 3-PBA and LH concentration, additionally Meeker et al. (2009b) [34] revealed positive associations with FSH and negative association with inhibin B and free androgen index. Radwan et al. (2014) [35] indicated that TDCCA was negatively related to the level of testosterone. Finally, the studies concerning the association between organophosphate pesticides and male reproductive hormones levels suggest that environmental exposure to pesticides may interfere with the male endocrine system. Meeker et al. (2006, 2007) [38,39] revealed the negative association between urinary metabolites of insecticides and testosterone, estradiol and free androgen index. Omoike et al. (2015) [40] showed such associations only with testosterone. In contrast Melgarejo et al. (2015) [37] revealed the positive association between urinary concentrations of organophosphate pesticide metabolites and $\mathrm{LH}$ and FSH.

There are possibly numerous factors contributing to the divergent results between studies. The various reproductive hormones levels used may be a possible explanation for the varied results. The use of different biomarkers to ascertain exposure may have some bearing on the statistical association, too. Other factors that may affect the differences may be the study population (general or from the infertility clinics) and number of participants in each of the study. Additionally, the choice of confounding factors included in the statistical analysis may also impact the results.

The results of the epidemiological studies concerning the exposure to EDCs are similar to those of animal studies [33], however, it must be noted that most animal studies to date have used dose levels that are much higher than what is encountered by environmentally exposed humans [17].

\section{Exposure assessment}

The exposure assessment in almost all reviews was based on the biomarkers of exposure. In the case of exposure to BPA, total urinary concentration (free + conjugated) was measured [12-15]. Phthalates were measured in urine [1822,25,26], semen [23,27] and serum [24]. Parabens, synthetic pyrethroids and organophosphate pesticides were measured in urine samples [30,33-40]. In most of the studies only one urine or various biological fluid samples were used for the exposure assessment purposes. One urine sample as a biomarker of exposure to EDCs may have resulted in substantial measurement error and attenuation of associations [41]. Janjua et al. (2007) [17] and Qing et al. (2017) [28] 
assessed 2 samples to evaluate the levels of phthalate. Meeker et al. $(2010,2011)[13,30]$ used 3 samples of urine to measure the concentration of BPA and parabens but the group of subjects with 2 or more urine samples was small. Whereas Galloway et al.'s (2010) [14] analyses were based on the 24-h urine specimens which is likely to be more accurate (participants were asked to collect the urine for $24 \mathrm{~h}$ in a vessel with a preservative) [14]. Non-persistent endocrine-disrupting chemicals are rapidly metabolized and excreted, and urinary metabolite concentrations only reflect exposure in the preceding 1 or 2 days [18]. However, despite within-person variability in urinary concentrations of endocrine-disrupting chemicals, a single spot is predictive of long-term exposure and provides good sensitivity to classify individuals [42].

\section{Confounders and potential risk factor}

The results of these studies were adjusted to many wellknown factors. Details of potential risk factors are shown in the Table 4. In the studies the age and body mass index (BMI) was usually controlled. Smoking status was included as a potential risk factor in all the studies. Only in 3 studies $[21,31,40]$ the smoking status was controlled by measuring the level of nicotine. The time of the day of blood/urine sample collection was adjusted in nearly a half of the studies [12,13,15,18,19,25,26,30,33,37,39], too. Several studies during which participants provided urine samples, urinary creatinine concentration was also considered to be a potential confounder [12,14,19,21,22,37,40]. Other factors such as ethnicity, medicine intake and chronic diseases were used as confounders in some studies [12,19,21,22,35,39,40]. Only Han et al. [22] and Melgarejo et al. [37] adjusted their study models by psychological tension and the number of stressful life events.

\section{Mechanism}

Endocrine-disrupting chemicals may interfere with the production, secretion, transportation, metabolism, re- ceptor binding, mediation of effects, and excretion of endogenous hormones which support endocrine homeostasis in the organism $[5,43]$. These chemicals may have anti-oestrogenic, oestrogenic, antigestagenic and antiandrogenic properties and are thought to mimic endogenous estrogens by entering the cell, binding to the receptor and activating transcription and may also antagonize normal androgen action [44]. In general, there is the number of information on the effect of exposure to EDCs on male reproductive hormones levels, indeed a considerable number of in vitro (sub-cellular or cellular) and in vivo (animal) screening tests for hormonal-activities of these substances have been developed [45]. Nonetheless, it is known that hormonal disruption alters the hypothalamic-pituitary endocrine function [37].

It was proven that BPA behaved similarly to natural estrogen-17- $\beta$ estradiol by inducing estrogen receptors but in the concentrations about one thousand higher $\left(10^{-6}\right.$ to $10^{-4} \mathrm{M}$ ) in comparison to estradiol [46]. Estrogenic activity of BPA has been well documented in the investigations on animals [47,48]. Additionally, BPA was proven to affect functions of androgens and prolactin [49]. On the other hand, phthalate esters act as agonists and/or antagonists of estrogen and androgen receptors via one or more hormonal receptors, although interaction of phthalate esters with the estrogen and androgen receptors requires certain size and bulkiness with alkyl groups [50]. Likewise, these endocrine disruptors may exhibit their activities by altering pregnane $\mathrm{X}$ receptor-regulated (PXR) steroid hormone metabolism [8]. Activation of PXR may increase the levels of endocrine-disrupting metabolites while at the same time altering the local bioavailability of endogenous androgens and estrogens [8]. Animals models documented that parabens possessed very weak estrogenic properties which may have resulted in alternations to male reproductive functions including testosterone secretion [51] but it had been hypothesized that the combination of several weakly acting substances may be additive or even synergistic and 


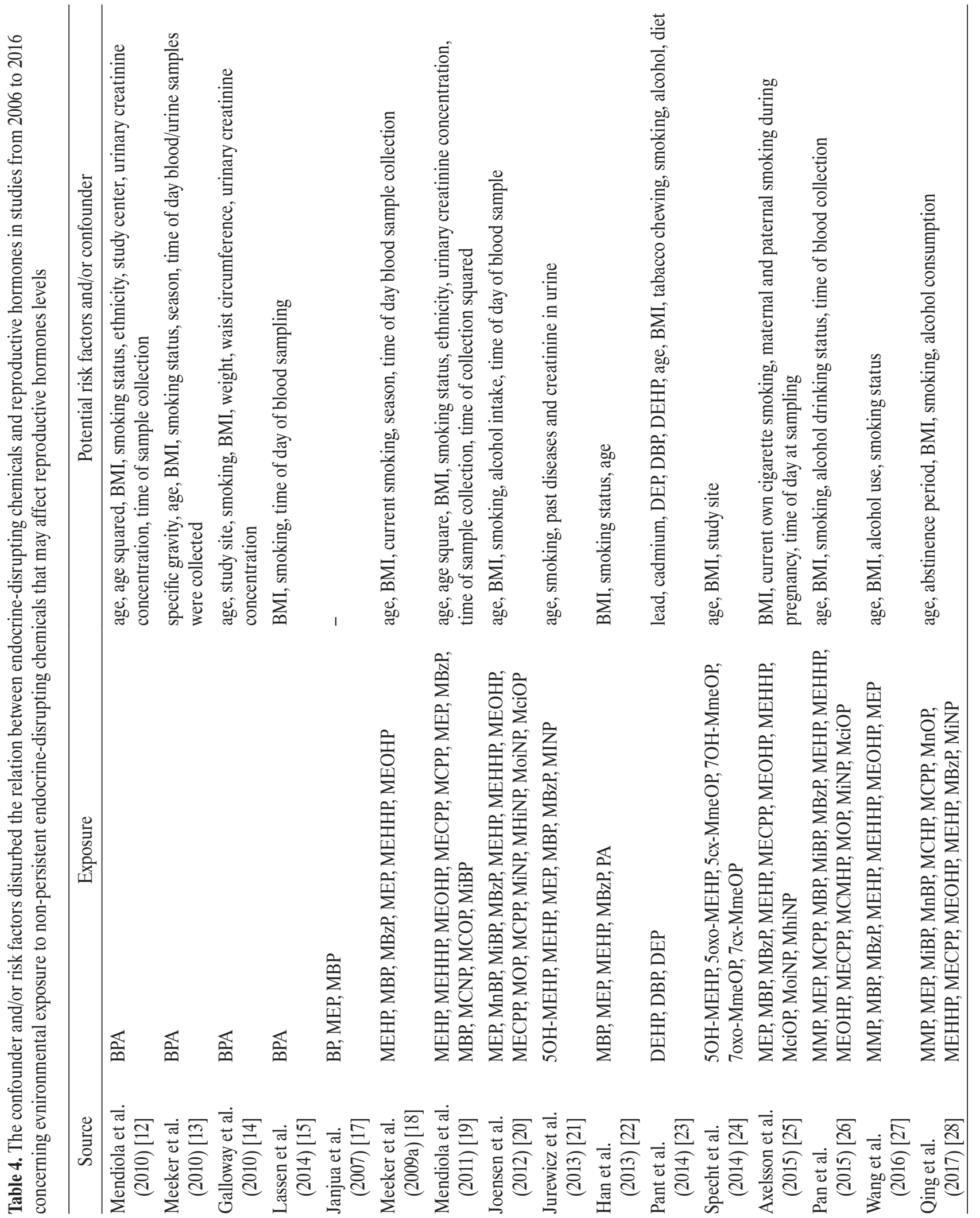




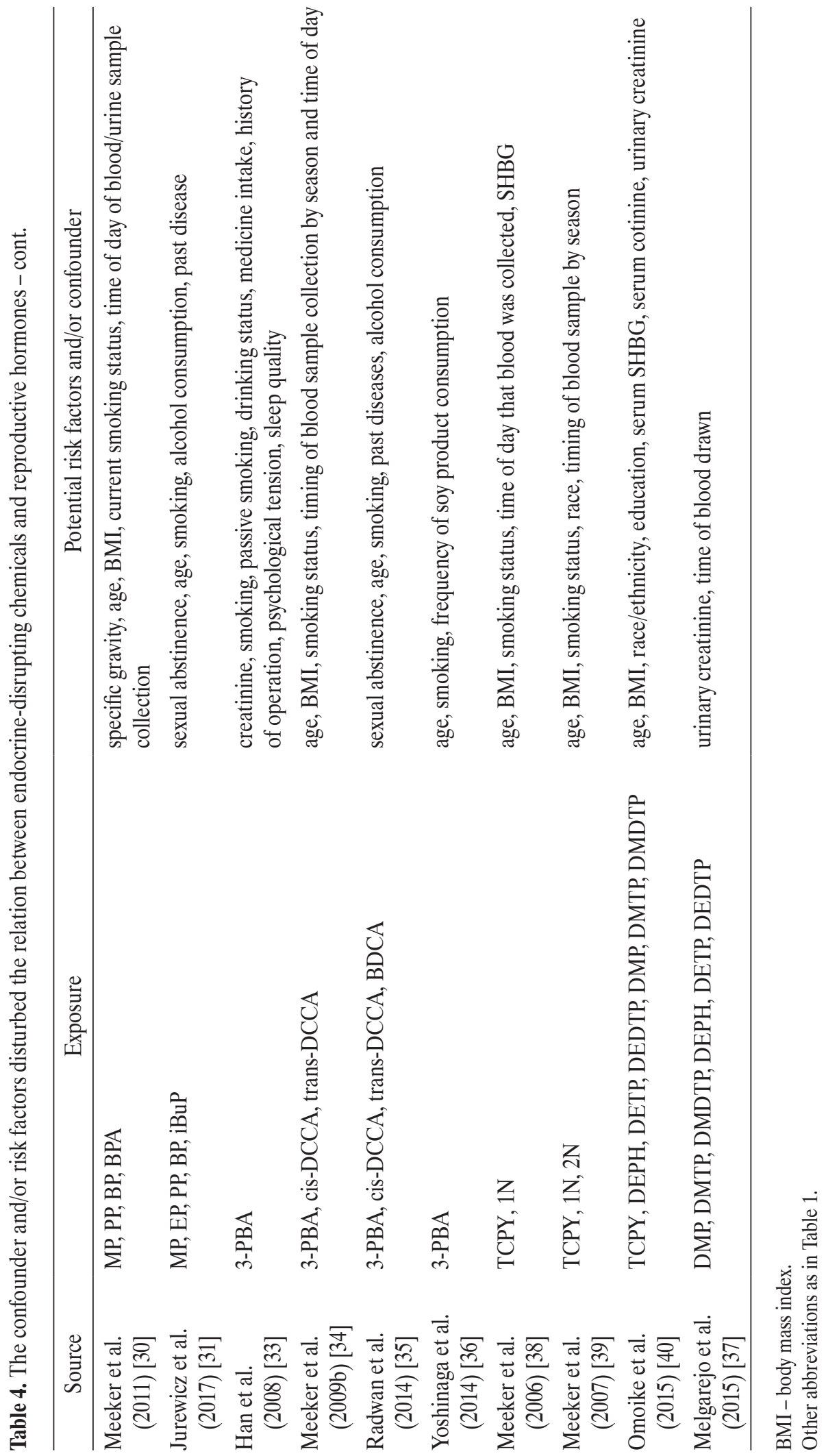


thereby yet produce adverse effects on the organism [45]. Whereas synthetic pyrethroids may affect estrogen receptors in Sertoli cells and have antiandrogenic properties by antagonizing the androgen receptor [52]. Some pyrethroids demonstrated deleterious effect on testosterone synthesis by the activity of enzyme for testosterone biosynthesis [36]. Finally, potential mechanisms for the association between organophosphate pesticides and reproductive hormones levels remain unclear [39]. The observed associations could be due to: impaired Leydig cell function [53], inhibited secretion of FSH or LH [54], reduced expression of steroidogenic enzymes or proteins [55].

The effect of endocrine-disrupting chemicals mediated through the activation or the inhibition of androgen and estrogen receptors are of primary concern for male reproductive health. Nevertheless, action through the aryl hydrocarbon receptor, which is cytosolic transcription factor with roles in developmental processes, xenobiotic metabolism and immunological responsiveness may also be important [4]. Estrogenic endocrine-disrupting chemicals may also exert more general effects through the induction of oxidative stress [56,57].

\section{Strengths and limitations of the studies}

The presented studies had several methodological strengths. The advantage of the studies includes the use of a detailed questionnaire information on demographic, medical, and life style risk factors performed among study participants. The filled-in questionnaires allowed to control the potential confounders in the statistical models. Furthermore, stringent criteria were used for excluding the subjects with drug treatment, occupational chemical exposures and medical history, which are related to reproductive hormones levels. In reviewed studies the sensitive immunoassay methods were used for measuring the levels of reproductive hormones. Additionally, exposure assessment based on biomarkers of exposure was the methodological strengths of the studies.
The limitations of the studies included the use of a single urine/semen sample to assess EDs exposure and a single serum sample to describe reproductive hormones levels. Endocrine disruptors are rapidly metabolized and excreted, therefore metabolite concentrations in urine/semen only reflect exposure status shortly before sampling. In most of the reviewed studies the reproductive hormones were measured in one serum sample. However, requiring multiple blood samples from participants may results in a reduced participation rate and lower statistical power. Another limitation is that subjects were selected mainly from an infertility clinics and the ability to generalize the results to the general population may be limited. The cross-sectional design of the presented studies restricted the ability to make conclusions regarding the relationship between EDs and reproductive hormones and didn't allow to rule out reverse causation, either. Finally, the temporal variability in metabolites of EDs from environmental exposure might have led to a bias during the studies.

\section{CONCLUSIONS}

The available epidemiology-related literature on the association of non-persistent endocrine-disrupting chemicals exposure with male reproductive hormones was reviewed. The results of 26 original papers are not consistent and demonstrate variability in study findings. Nonetheless, the results suggest that environmental exposure to nonpersistent endocrine-disrupting chemicals may affect male reproductive hormones levels.

The widespread distribution of environmental chemicals and the detection of these substances within human body indicate that humans are continually exposed to a variety of endocrine-disrupting chemicals through multiple sources. Data is alarming and although the association between EDs exposure and human disorders is difficult to establish, there is growing evidence to suggest a potential interference. In future more related studies should be conducted to confirm the associations. 


\section{REFERENCES}

1. Zegers-Hochschild F, Adamson GD, de Mouzon J, Ishihara $\mathrm{O}$, Mansour R, Nygren K, et al. International Comitee for Monitoring Assisted reproductive Technology (ICMART) and the World Health Organization (WHO) revised glossary of ART terminology. Fertil Steril. 2009;92(5):1520-4, https:// doi.org/10.1016/j.fertnstert.2009.09.009.

2. Practice Committee of the American Society for Reproductive Medicine in collaboration with the Society for Reproductive Endocrinology and Infertility. Optimizing natural fertility. Fertil Steril. 2008;90(5):1-6, https://doi.org/10.1016/ j.fertnstert.2008.08.122.

3. Skakkebaek NE, Rajpert-De Meyts E, Louise GM, Toppari J, Andersson AM, Eisenberg ML, et al. Male reproductive disorders and fertility trends: Influences of environment and genetic susceptibility. Physiol Rev. 2016;96(1):55-97, https://doi. org/10.1152/physrev.00017.2015.

4. Knez J. Endocrine-disrupting chemicals and male reproductive health. Reprod Biomed Online. 2013;26:440-8, https:// doi.org/10.1016/j.rbmo.2013.02.005.

5. Kavlock RJ, Daston GP, DeRosa C, Fenner-Crisp P, Gray LE, Kaattari S, et al. Research needs for the risk assessment of health and environmental effect of endocrine disruptors: A report of the USEPA-sponsored workshop. Environ Health Perspect. 1996;104(4):715-40.

6. Diamanti-Kandarakis E, Bourguignon JP, Giudice LC, Hauser R, Prins GS, Soto AM, et al. Endocrine-disrupting chemicals: An Endocrine Society scientific statement. Endocr Rev. 2009;30(4):293-342, https://doi.org/10.1210/er.2009-0002.

7. World Health Organization, United Nations Environment Programme. Sate of science of endocrine disrupting chemicals 2012. The Organization, The Programme: Geneva; 2013.

8. Tabb MM, Blumberg B. New modes of action for endocrinedisrupting chemicals. Mol Endocrinol. 2005;20(3):475-82, https://doi.org/10.1210/me.2004-0513.

9. Le Moal J, Sharpe RM, Jørgensen N, Levine H, Jurewicz J, Mendiola J, et al. Toward a multi-country monitoring system of reproductive health in the context of endocrine disrupting chemical exposure. Eur J Public Health. 2015;26(1):76-83, https://doi.org/10.1093/eurpub/ckv153.

10. Hueiwang AJ. Exposure to endocrine disrupting chemicals and male reproductive health. Front Public Health. 2014;2(55):1-12, https://doi.org/10.3389/fpubh.2014.00055.

11. Gao C, Liu L, Ma W, Zhu N, Jiang L, Ren N, et al. Bisphenol $\mathrm{A}$ in urine of Chinese young adults: Concentrations and source of exposure. Bull Environ Contam Toxicol. 2016;96(2): 162-7, https://doi.org/10.1007/s00128-015-1703-5.

12. Mendiola J, Jørgensen N, Andersson AM, Calafat AM, Ye X, Redmon JB, et al. Are environmental levels of bisphenol A associated with reproductive function in fertile men? Environ Health Perspect. 2010;118(9):1286-91, https://doi. org/10.1289/ehp.1002037.

13. Meeker JD, Calafat AM, Hauser R. Urinary bisphenol A concentrations in relation to serum thyroid and reproductive hormone levels in men from an infertility clinic. Environ Sci Technol. 2010;44(4):1-15, https://doi.org/10.1021/es9028292.

14. Galloway T, Cipelli R, Guralnik J, Ferrucci L, Bandinelli S, Corsi AM, et al. Daily bisphenol A excretion and association with sex hormone concentrations: Results from InCHIANTI Adult Population Study. Environ Health Perspect. 2010;118(11):1603-8, https://doi.org/10.1289/ehp. 1002367.

15. Lassen TH, Frederiksen H, Jensen TK, Petersen JH, Joensen UN, Main KM, et al. Urinary bisphenol A levels in young men: Association with reproductive hormones and semen quality. Environ Health Perspect. 2014;122(5):47884, https://doi.org/10.1289/ehp.1307309.

16. Latini G, Del Vecchio A, Massaro M, Verrotti A, De Felice C. Phthalate exposure and male infertility. Toxicol. 2006;226:90-8, https://doi.org/10.1016/j.tox.2006.07.011.

17. Janjua NR, Mortensen GK, Andersson AM, Kongshoj B, Skakkebaek NE, Wulf HC. Systemic uptake of diethyl phthalate, dibutyl phthalate, and butyl paraben following whole-body topical application and reproductive and thyroid hormone levels in humans. Environ Sci Technol. 2007;41(15):5564-70, https://doi.org/10.1021/es0628755. 
18. Meeker JD, Calafat AM, Hauser R. Urinary metabolites of di(2-ethylhexyl) phthalate are associated with decreased steroid hormone levels in adult men. J Androl. 2009a;30(3):28797, https://doi.org/10.2164/jandrol.108.006403.

19. Mendiola J, Jørgensen N, Andersson AM, Calafat AM, Silva MJ, Redmon JB, et al. Associations between urinary metabolites of di(2-ethylhexyl) phthalate and reproductive hormones in fertile men. Int J Androl. 2011;34(4):369-78, https://doi.org/10.1111/j.1365-2605.2010.01095.x.

20. Joensen UN, Frederiksen H, Blomberg Jensen M, Lauritsen MP, Olesen IA, Lassen TH, et al. Phthalate excretion pattern and testicular function: A study of 881 healthy Danish men. Environ Health Persp. 2012;120(10):1397-403, https://doi.org/10.1289/ehp.1205113.

21. Jurewicz J, Radwan M, Sobala W, Ligocka D, Radwan P, Bochenek M, et al. Human urinary phthalate metabolites level and main semen parameters, sperm chromatin structure, sperm aneuploidy and reproductive hormones. Reprod Toxicol. 2013;42(2013):232-41, https://doi.org/10.1016/j.reprotox.2013.10.001.

22. Han X, Cui Z, Zhou N, Ma M, Li L, Li Y, et al. Urinary phthalate metabolites and male reproductive function parameters in Chongqing general population, China. Int J Hyg Envir Health. 2013;217(2014):271-8, https://doi.org/ 10.1016/j.ijheh.2013.06.006.

23. Pant N, Kumar G, Upadhyay AD, Patel DK, Gupta YK, Chaturvedi PK. Reproductive toxicity of lead, cadmium, and phthalate exposure in men. Environ Sci Pollut Res. 2014;21:11066-74, https://doi.org/10.1007/s11356-0142986-5.

24. Specht IO, Toft G, Hougaard KS, Lindh CH, Lenters V, Jönsson BAG, et al. Association between serum phthalates and biomarkers of reproductive function in 589 adult men. Environ Int. 2014;66(2014):146-56, https://doi.org/10.1016/ j.envint.2014.02.002.

25. Axelsson J, Rylander L, Rignell-Hydbom A, Jönsson BAG, Lindh $\mathrm{CH}$, Giwercman A. Phthalate exposure and reproductive parameters in young men from the general Swedish population. Environ Int. 2015;85(2015):54-60, https://doi. org/10.1016/j.envint.2015.07.005.

26. Pan Y, Jing J, Dong F, Yao Q, Zhang W, Zhang H, et al. Association between phthalate metabolites and biomarkers of reproductive function in 1066 Chinese men of reproductive age. J Hazard Mater. 2015;300(2015):729-36, https://doi. org/10.1016/j.jhazmat.2015.08.011.

27. Wang YX, Zeng Q, Sun Y, Yang P, Wang P, Li J, et al. Semen phthalate metabolites, semen quality parameters and serum reproductive hormones: A cross-sectional study in China. Environ Pollut. 2016;211(2016):173-82, https://doi. org/10.1016/j.envpol.2015.12.052.

28. Qing C, Huan Y, Niya Z, Lei S, Huaqiong B, Lu T, et al. Phthalate exposure, even below US EPA references doses, was associated with semen quality and reproductive hormones: Prospective MARHCS study in general population. Environ Int. 2017;104:58-68, https://doi.org/10.1016/j.envint.2017.04.005.

29. Tavares RS, Martins FC, Oliveira PJ, Ramalho-Santos J, Peixoto FP. Parabens in male infertility - Is there a mitochondrial connection? Reprod Toxicol. 2009;27:1-7, https:// doi.org/10.1016/j.reprotox.2008.10.002.

30. Meeker JD, Yang T, Ye X, Calafat AM, Hauser R. Urinary concentrations of parabens and serum hormone levels, semen quality parameters, and sperm DNA damage. Environ Health Persp. 2011;119(2):252-7, https://doi.org/10.1289/ ehp.1002238.

31. Jurewicz J, Radwan M, Wielgomas B, Dziewirska E, Karwacka A, Klimowska A, et al. Human semen quality, sperm DNA damage, and the level of reproductive hormones in relations to urinary concentrations of parabens. J Occup Environ Med. 2017;59(11):1034-40, https://doi.org/10.1097/ JOM.0000000000001106.

32. Saillenfait AM, Ndiaye D, Sabaté JP. Pyrethroids: Exposure and health effects - An update. Int J Hyg Environ Health. 2015;218(3):281-92, https://doi.org/10.1016/j.ijheh.2015.01.002.

33. Han Y, Xia Y, Han J, Zhou J, Wang S, Zhu P, et al. The relationship of 3-PBA pyrethroids metabolite and male 
reproductive hormones among non-occupational exposure males. Chemosphere. 2008;72(2008):785-90, https://doi.org/ 10.1016/j.chemosphere.2008.03.058.

34. Meeker JD, Barr DB, Hauser R. Pyrethroid insecticide metabolites are associated with serum hormone levels in adult men. Reprod Toxicol. 2009b;27(2):155-60, https://doi. org/10.1016/j.reprotox.2008.12.012.

35. Radwan M, Jurewicz J, Wielgomas B, Sobala W, Piskunowicz $\mathrm{M}$, Radwan $\mathrm{P}$, et al. Semen quality and the level of reproductive hormones after environmental exposure to pyrethroids. JOEM. 2014;56(11):1113-9, https://doi.org/10.1097/ JOM.0000000000000297.

36. Yoshinaga J, Imai K, Shiraishi H, Nozawa S, Yoshiike M, Mieno MN, et al. Pyrethroid insecticide exposure and reproductive hormone levels in healthy Japanese male subjects. Andrology. 2014;2:416-20, https://doi.org/10.1111/j.2047-2927. 2014.00202.x.

37. Melgarejo M, Mendiola J, Koch HM, Moñino-Gracía M, Noguera-Velasco JA, Torres-Cantero AM. Association between urinary organophosphate pesticide metabolite levels and reproductive parameters in men from an infertility clinic. Environ Res. 2015;137:292-8, https://doi.org/10.1016/ j.envres.2015.01.004.

38. Meeker JD, Ryan L, Barr DB, Hauser R. Exposure to nonpersistent insecticides and male reproductive hormones. Epidemiology. 2006;17(1):61-8, https://doi.org/10.1097/01. ede.0000190602.14691.70.

39. Meeker JD, Ravi SR, Barr DB, Hauser R. Circulating estradiol in men is inversely related to urinary metabolites of nonpersistent insecticides. Reprod Toxicol. 2007;25(2008):18491, https://doi.org/10.1016/j.reprotox.2007.12.005.

40. Omoike O, Lewis RC, Meeker JD. Association between urinary biomarkers of exposure to organophosphate insecticides and serum reproductive hormones in men from NHANES 1999-2002. Reprod Toxicol. 2015;53(2015):99104, https://doi.org/10.1016/j.reprotox.2015.04.005.

41. Mínguez-Alarcón L, Hauser R, Gaskins AJ. Effects of bisphenol A on male and couple reproductive health: A review.
Fertil Steril. 2016;106(4):864-70, https://doi.org/10.1016/ j.fertnstert.2016.07.1118.

42. Mahalingaiah S, Meeker JD, Pearson KR, Calafat AM, Ye X, Petrozza J, et al. Temporal variability and predictors of urinary bisphenol A concentrations in men and women. Environ Health Perspect. 2008;116:173-8, https://doi. org/10.1289/ehp.10605.

43. Latini G, Del Vecchio A, Massaro M, Verrotti A, De Felice $\mathrm{C}$. Phthalate exposure and male infertility. Toxicology. 2006;226:90-8, https://doi.org/10.1016/j.tox.2006.07.011.

44. Sultan C, Balaguer P, Terouanne B, Georget V, Paris F, Jeandel $\mathrm{C}$, et al. Environmental xenoestrogens, antiandrogens and disordes of male sexual differentiation. Mol Cell Endocrinol. 2001;178:99-105, https://doi.org/10.1016/S0303-7207 (01)00430-0.

45. Nohynek GJ, Borgert CJ, Dietrich D, Rozman KK. Endocrine disruption: Fact or urban legend? Toxicol Lett. 2013; 223:295-305, https://doi.org/10.1016/j.toxlet.2013.10.022.

46. Iso T, Watanable T, Iwamoto T, Shimamoto A, Furuichi Y. DNA damage caused by bisphenol A and estradiol trough estrogenic activity. Biol Pharm Bull. 2006;29(2):206-10, https://doi.org/10.1248/bpb.29.206.

47. Alonso-Magdalena P, Ropero A, Rosiano S, Garcia-Arevalo M, Ripolloi C, Fuentes E, et al. Bisphenol A acts as a potent estrogen via non-classical estrogen triggered pathways. Mol Cell Endocrinol. 2012;355:201-07, https://doi. org/10.1016/j.mce.2011.12.012.

48. Talsness CE, Andrade AJM, Kuriyama SN, Taylor JA, vom Saal FS. Components of plastic: Experimental studies in animals and relevance for human health. Philos Trans R Soc Lond B Biol Sci. 2009;364(1526):2079-96, https://doi. org/10.1098/rstb.2008.0281.

49. Fenichel P, Chevalier N, Brucker-Davis F. Bisphenol A: An endocrine and metabolic disruptor. Ann Endocrinol. 2013;73(3):211-20, https://doi.org/10.1016/j.ando.2013. 04.002 .

50. Takeuchi S, Iida M, Kobayashi S, Jin K, Matsuda T, Kojima H. Differential effects of phthalate esters on transcriptional 
activities via human estrogen receptors $\alpha$ and $\beta$, and androgen receptor. Toxicology. 2005;210:223-33, https://doi. org/10.1016/j.tox.2005.02.002.

51. Darbre PD, Harvey PW. Paraben esters: Review of recent studies of endocrine toxicity, absorption, esterase and human exposure, and discussion of potential human health risks. J Appl Toxicol. 2008;28:561-78, https://doi.org/10.1002/jat.1358.

52. Zhang J, Zhu W, Zheng Y, Yang J, Zhu X. The antiandrogenic activity of pyrethroid pesticides cyfluthrin and $\beta$-cyfluthrin. Reprod Toxicol. 2008;25:491-6, https://doi. org/10.1016/j.reprotox.2008.05.054.

53. Dirican EK, Kalender Y. Dichlorvos-induced testicular toxicity in male rats and the protective role of vitamins $\mathrm{C}$ and E. Exp Toxicol Pathol. 2012;64:821-30, https://doi. org/10.1016/j.etp.2011.03.002.
54. Joshi SC, Mathur R, Gulati N. Testicular toxicity of chlorpyrifos (an organophosphate pesticide) in albino rat. Toxicol Ind Health. 2007;23:439-44.

55. Viswanath G, Chatterjee S, Dabral S, Nanguneri SR, Divya G, Roy P. Anti-androgenic endocrine disrupting activities of chlorpyrifos and piperophos. J Steroid Biochem Mol Biol. 2010;120:22-9, https://doi.org/10.1016/j.jsbmb.2010.02.032.

56. Aydoğan M, Korkmaz A, Barlas N, Kolankaya D. The effect of vitamin $\mathrm{C}$ on bisphenol A, nonylphenol and octylphenol induced brain damages of male rats. Toxicology. 2008;249:35-9, https://doi.org/10.1016/j.tox.2008.04.002.

57. Gong Y, Han XD. Nonylphenol-induced oxidative stress and cytotoxicity in testicular sertoli cells. Reprod Toxicol. 2006;22:623-30, https://doi.org/10.1016/j.reprotox.2006. 04.019 .

This work is available in Open Access model and licensed under a Creative Commons Attribution-NonCommercial 3.0 Poland License - http://creativecommons.org/ licenses/by-nc/3.0/pl/deed.en. 